\title{
Chemical defenses of three Glossodoris nudibranchs and their dietary Hyrtios sponges
}

\author{
Shelly D. Rogers, Valerie J. Paul \\ University of Guam Marine Laboratory, UOG Station, Mangilao, Guam 96923, USA
}

\begin{abstract}
Dorid nudibranchs prey upon sponges, tunicates, and bryozoans which generally contain high levels of secondary metabolites. On Guam, the nudibranch Glossodoris pallida was found in Apra Harbor exclusively on a variety of Hyrtios erecta sponge containing a high concentration of the secondary metabolite scalaradial. Glossodoris hikeurensis and G. cincta preyed upon a second variety of $H$. erecta from Cocos Lagoon which did not contain scalaradial, but rather had high concentrations of heteronemin, a secondary metabolite that was not found in the variety of $H$. erecta from Apra Harbor. In laboratory tests, G. pallida strongly preferred $H$. erecta from Apra Harbor while G. hikeurensis and $G$. cincta preferred $H$. erecta from Cocos Lagoon. $H$. erecta from Apra Harbor contained 3 major secondary metabolites, scalaradial, deoxyscalarin, and scalarin, as well as several minor metabolites. G. pallida sequestered only 2 of these metabolites, scalaradial and deoxyscalarin. H. erecta from Cocos Lagoon contained primarily heteronemin, whereas its predators G. hikeurensis and $G$. cincta contained heteronemin and episcalaradial. Results of feeding deterrence assays with extracts and isolated metabolites differed when tested toward different predators, indicating that these secondary metabolites may be deterrent toward some but not all potential predators. Organic extracts of the Hyrtios sponges were deterrent at half of natural concentrations in some laboratory and field feeding assays while organic extracts of nudibranchs were never deterrent at half of natural concentrations. Heteronemin deterred feeding by fishes in most assays; however, scalaradial did not deter feeding by predatory fishes in most field or laboratory assays and was only deterrent at high concentrations in one assay. Minor metabolites or synergistic effects among sponge metabolites may play a key role in determining feeding deterrence for these sponges. Glossodoris nudibranchs probably excrete or alter some secondary metabolites from their diets.
\end{abstract}

\section{INTRODUCTION}

Dorid nudibranchs specialize in feeding on sponges or other invertebrates that are rarely eaten by other predators. Nudibranch prey items typically contain a high level of secondary metabolites, particularly terpenoids, alkaloids, and acetogenins, that are biosynthesized by the prey organism but are apparently not needed for their basic metabolism. Many of these secondary metabolites are biologically active, i.e. they possess antimicrobial activity, anti-inflammatory activity, cytotoxicity, or icthyotoxicity (reviewed by Minale 1978, Bakus 1981, Bakus et al. 1986, Gunthorpe \& Cameron 1987). Some are known to deter feeding by potential predators and thus may help to protect the sponge from being eaten (Pawlik et al. 1988). Sponge chemical defenses do not appear to be effective against specialist predators, since nudibranchs specialize on certain sponges and may accumulate noxious sponge compounds and store them in glands to be used for their own defense. The chemical relationship between nudibranchs and sponges has been reviewed by Thompson et al. (1982), Faulkner \& Ghiselin (1983), Faulkner (1984, 1988, in press), and Karuso (1987).

Many dorid nudibranchs are currently hypothesized to be defended by sequestered compounds, especially if their known prey items contain a high concentration of secondary metabolites (Faulkner \& Ghiselin 1983). This hypothesis has not been experimentally tested for most species of nudibranchs. Some nudibranchs may expel or alter noxious compounds so that they are no longer deterrent. This could occur passively as the compounds decompose in the digestive gland or it could be actively mediated by enzymes from the nudibranch. It is also possible that nudibranchs may not accumulate enough of these defensive compounds to deter predators. At natural concentrations, the extracts of several species of Phyllidia nudibranchs were not 
found to be significant feeding deterrents (Karuso 1987. Paul \& Rogers unpubl.). Only a small portion of all dorid nudibranch species have been extracted and tested for feeding deterrence toward potential predators (Thompson et al. 1982, Faulkner \& Ghiselin 1983, Carté \& Faulkner 1986, Karuso 1987, Pawlik et al. 1988, Paul et al. 1990). Therefore, further work is needed to test the hypothesis that nudibranchs sequester deterrent compounds from their diets to use as chemical defenses against potential predators.

The physiological mechanisms by which nudibranchs transport and accumulate secondary metabolites are not known. Most of these metabolites appear to be stored in specialized glands (Thompson 1960,1976 ), and have been shown to be more concentrated in the dorsal mantle and digestive gland in several species (Thompson et al. 1982, Pawlik et al. 1988). Some nudibranchs may be capable of de novo synthesis of deterrent metabolites; Dendrodoris grandiflora and Archidoris montereyensis are able to produce their own deterrent compounds from simple carbon molecules (Gustafson et al. 1984, Cimino et al. 1985, Faulkner et al. 1990). However, most nudibranchs appear to obtain their major secondary metabolites through their diet. Generally, a close relationship exists between the secondary metabolites of dorid nudibranchs and their dietary sponges (reviewed by Faulkner 1984, 1988, in press, Karuso 1987, Faulkner et al. 1990).

This study focuses on the chemical ecology of 3 nudibranchs in the genus Glossodoris (family Chromodorididae), specifically Glossodoris pallida, G. hikeurensis and $G$. cincta. The purpose of this study was to examine the biochemical relationship between the Glossodoris nudibranchs and their dietary Hyrtios sponges. The central hypothesis was that Glossodoris nudibranchs are attracted to and selectively accumulate secondary metabolites found in their food sponges and that these metabolites deter feeding by potential predators. We focused especially on G. pallida because it could be collected more consistently and in larger numbers than the other 2 Glossodoris species. Three questions were addressed: (1) Is Glossodoris pallida attracted exclusively by its food sponge $H$. erecta? (2) Do Glossodoris nudibranchs accumulate and concentrate secondary metabolites from their food sponges? (3) Do the crude extracts or major secondary metabolites of Glossodoris nudibranchs or their food sponges deter feeding by potential generalist predators?

\section{STUDY ORGANISMS AND SITES}

Glossodoris pallida is a small, white nudibranch, growing up to ca $2.5 \mathrm{~cm}$ length. G. hikeurensis and $G$.

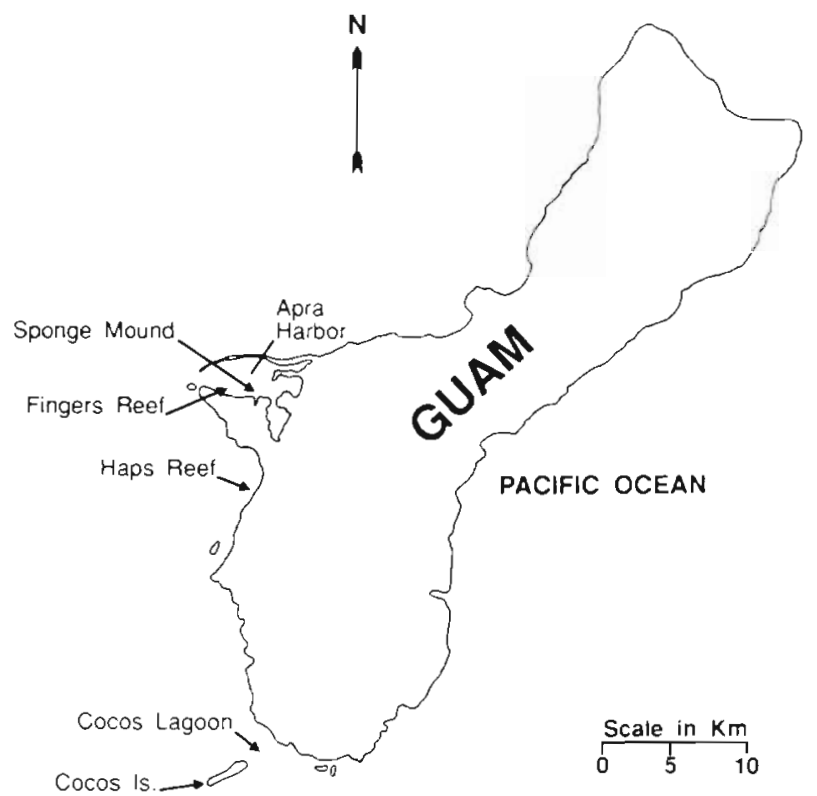

Fig. 1. Map of Guam showing study sites

cincta are larger nudibranchs growing up to $\mathrm{ca} 10 \mathrm{~cm}$ length. $G$. hikeurensis and $G$. cincta look very alike and are brown. Glossodoris nudibranchs typically feed on sponges in the order Dictyoceratida (Schulte et al. 1980, Okuda \& Scheuer 1985, pers. obs.). The Dictyoceratida are among several orders of the class Desmospongiae that possess a fibrous rather than a mineral skeleton (Bergquist 1980) and contain a relatively high. concentration of secondary metabolites, including a variety of terpenes, particularly sesterterpenes (Bergquist \& Wells 1983).

On Guam, Glossodoris pallida feeds almost exclusively on the sponge Hyrtios erecta (order Dictyoceratida; family Thorectidae). Large, constant popula-

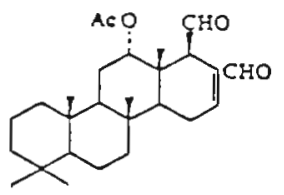

scalaradial

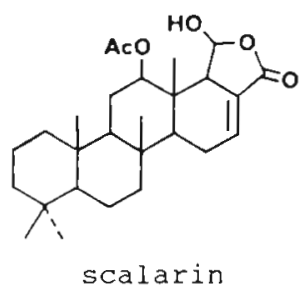

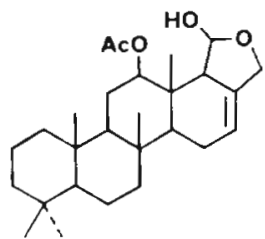

deoxyscalarin

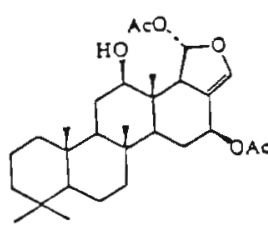

heteronemin
Fig. 2. Major metabolites of Hyrtios erecta-A (scalaradial, scalarin, deoxyscalarin) and Hyrtios erecta-C (heteronemin) 
tions of the sponge and nudibranch exist at a depth of 20 to $30 \mathrm{~m}$ on a pinnacle known as Sponge Mound in Apra Harbor, Guam (Fig. 1). H. erecta has been extensively collected and studied in Australia, the Red Sea, Palau and Polynesia (Crews et al. 1985, Crews \& Bescansa 1986, Paul pers. comm.). G. pallida has not been reported to feed on $H$. erecta in any part of the world except Guam. The major metabolite of the sponge from Apra Harbor on Guam is scalaradial (Cimino et al. 1974) (Fig. 2). H. erecta populations from Australia, the Red Sea, and Palau are reported to contain a different, but closely related major secondary metabolite, heteronemin (Kazlauskas et al. 1976) (Fig. 2), which is not found in $H$. erecta from Apra Harbor. Scalaradial has been reported as a secondary metabolite of $H$. erecta from the Kingdom of Tonga, Polynesia, but in very low concentrations, with heteronemin still being the major metabolite (Crews \& Bescansa 1986). Because of its unique chemistry, $H$. erecta from Apra Harbor will be referred to as $H$. erecta-A for the remainder of this paper.

Another type of Hyrtios erecta was discovered from Cocos Lagoon, Guam (Fig. 1) and will be referred to as $H$. erecta-C. The surface skeleton of $H$. erecta-C differs slightly from $H$. erecta-A and $H$. erecta from other parts of the world. It is uncertain whether $H$. erecta-C is a new species or simply an unusual growth form (Bergquist pers. comm.). The chemistry of $H$. erecta-C is similar to the chemistry of $H$. erecta reported in the literature since it possesses heteronemin as its major metabolite.

Hyrtios altum is closely related to, and found in close proximity to $H$. erecta-A on Sponge Mound Reef. The chemistry of $H$. altum is most similar to $H$. erecta-C, with heteronemin as the major metabolite.

Even though Glossodoris pallida is abundant on Hyrtios erecta-A, the nudibranch has never been sighted on $H$. altum or on $H$. erecta-C. In contrast, $G$. hikeurensis and $G$. cincta are found feeding on $H$, erecta-C in or near Cocos Lagoon, and have never been sighted feeding on $H$. erecta-A (Rogers 1989).

\section{MATERIALS AND METHODS}

Preference studies. Field observations and laboratory preference experiments were used to determine nudibranch feeding preferences. Field observations involved weekly dives on Sponge Mound where Glossodoris pallida and Hyrtios erecta-A are abundant. Seventy-five $H$. erecta-A were haphazardly selected and tagged with flagging tape. The number of $G$. pallida on each tagged sponge was recorded approximately twice each month for 10 mo, November 1987 through August 1988. At the same time, H. altum in the vicinity were examined for nudibranchs. We were also interested in the dispersion of the nudibranchs because a clumped distribution might indicate that some sponges were less suitable as food, or that individuals were attracted to other G. pallida feeding on $H$. erectaA. To test whether the nudibranchs were randomly distributed on sponges or clumped, we calculated the coefficient of dispersion (CD) for each date. We tested the null hypothesis that the variance was equal to the mean $(C D=1$, random distribution) by a Chi-square test (Sokal \& Rohlf 1981).

Approximately 15 dives were made in Cocos Lagoon where we observed Glossodoris hikeurensis and $G$. cincta and recorded the substrate upon which they were crawling. G. cincta was also observed on the Sponge Mound.

In the laboratory, Glossodoris pallida was tested for attraction toward Hyrtios sponges and sponge metabolites. Twelve nudibranchs were placed individually into twelve $300 \mathrm{ml}$ flow-through tanks. Nudibranchs were individually offered a choice between a piece of Hyrtios sponge and a piece of coral rubble (as a control). One G. pallida was placed in the middle of each aquarium, and observed hourly to see if it was in contact with a sponge or the coral rubble. The nudibranch was recorded as being in contact with whatever object its mouth was touching. Replicates were not used if the nudibranch was not noted on a sponge or piece of coral rubble at least 3 of 12 times. Individual nudibranchs were recorded as preferring the item upon which they were observed most (ties were dropped). Significance of preferences was assessed with a Binomial test (2-tailed)

Using similar techniques, several other preference experiments were conducted. Glossodoris pallida was tested to see if it preferred Hyrtios erecta-A over either $H$. erecta-C or $H$. altum. G. pallida was also tested to determine if there was a preference between $H$. erecta$\mathrm{C}$ and $H$. altum. Preferences between the light inner matrix and the dark surface layer of $H$. erecta-A were also tested. These experiments were completed by matching portions of the matrix with similar size portions of the surface of the same piece of $H$. erecta-A, then placing each matched pair in a test tank and observing the nudibranch's reaction as before. Finally, several pieces of $H$. erecta-A that had been grazed by G. pallida in the field were collected. The portion of the sponge that was grazed by the nudibranch was cut out and offered to nudibranchs in replicate tanks along with a portion of the same sponge that had not been grazed.

Chemical analysis. To prepare an extract, the nudibranch or sponge was first freeze-dried. Then, sponges were blended in a 1.1 mixture of acetone: methanol and filtered immediately. This was repeated (usually 
3 to 5 times) until all visible metabolites had been extracted from the sponge. Nudibranchs were soaked in 2 consecutive baths of acetone, which were later combined. Water-soluble metabolites were extracted from $H$. erecta-A and $H$. altum. This was done by homogenizing the sponge in tap water in a blender, followed by filtering and freeze-drying. The percent yield of extract from each organism was calculated by dividing the weight of the extract by the dry weight of the organism and multiplying by 100 .

All organic extracts were compared by thin layer chromatography (TLC). Compounds were usually identified by comparing the extracts to known standards. Major metabolites were isolated by silica gel flash chromatography followed by high performance liquid chromatography (HPLC). Metabolites were identified by proton nuclear magnetic resonance spectroscopy (NMR), comparing observed values to those reported in the literature. Concentrations of the metabolites within the sponge extracts were determined based on the amounts isolated by HPLC and are therefore conservative since some material is lost during isolation. Concentrations of metabolites in the nudibranch and egg mass extracts were estimated from proton NMR spectra of the extracts.

To test whether previously grazed Hyrtios erecta-A differed chemically from ungrazed sponge, 8 sponges with 5 or more nudibranchs on each and 12 sponges with no nudibranchs were collected. Comparisons of TLC results and extract concentrations were used to determine if there were any qualitative chemical differences between the grazed and ungrazed sponges. Chemical differences between the inner matrix and the outer surface of $H$. erecta-A were also examined by similar methods.

Glossodoris pallida was also tested for acid secretion following methods used by Edmunds (1968). Five living nudibranchs were removed from water, prodded to release a milky secretion, and $\mathrm{pH}$ indicator paper $(\mathrm{pH} 1$ to 11 ) was placed on their dorsal and ventral surfaces to determine the acidity of their secretions.

Predator deterrence experiments. To determine if Glossodoris pallida were palatable to fish, 10 nudibranchs were placed, one at a time, in an aquarium. with 7 hungry predatory fish. Although this technique was crude, it has proven to be useful in determining possibilities of feeding deterrent compounds (Herdman \& Clubb 1892, Crossland 1911, Thompson 1960). Pieces of fish meat, the same color and size as the nudibranch, were offered to the aquarium fish in between each offered nudibranch. The fishes' reactions were recorded. Fish used were Rhinecanthus aculeatus (Picasso trigger fish), Halichoeres trimaculatus (3-spotted wrasse), Lutjanus monstigmus (snapper) and Epibulus insidiator (sling-jaw wrasse). Similar experi- ments were conducted in the field at Fingers Reef in Apra Harbor on Guam with G. pallida and their egg masses and equal size pieces of the sponge $H$. erectaA. Sponge pieces, nudibranchs, and egg masses were offered to fish in the water column alternately with similar-sized pieces of squid. The responses of different species of fish were noted.

Crude extracts and pure metabolites were tested against the pufferfish Canthigaster solandri in the laboratory and against natural populations of predatory fishes in the field. C. solandri feeds on benthic algae, ascidians, and other small benthic invertebrates (Amesbury \& Myers 1982) and could be a potential predator of Glossodoris nudibranchs. Several C. solandri were trained to feed on agar-based food cubes in the laboratory. The food was made by heating agar, brine shrimp eggs, freeze-dried krill and water to boiling, then allowing the solution to cool until it jelled.

In order to test a compound, it was dissolved in a small quantity of acetone or a mixture of acetone and hexane or methanol, depending upon its polarity. The dissolved compound was added to the food mixture after heating, while it was still warm. The mix was stirred for $30 \mathrm{~s}$ while the solvent evaporated to ensure even distribution of the compound. Finally, the mix was poured into a tray and allowed to cool until firm. Control cubes were made the same way using solvents only. All compounds were tested at natural concentrations or below. Concentrations of the treated cubes were calculated based on the percent of the metabolite per dry weight of the food cube

Four treated and 4 control cubes were attached to polypropylene lines and offered to groups of 2 or 3 Canthigaster solandri in separate chambers within a large outdoor aquarium. A minimum of 7 groups of fish was used. Assays lasted approximately $30 \mathrm{~min}$. The amount eaten was determined by measuring the change in weight of the treated and control cubes for each set of fish. One treated-and-control pair of lines was placed in a chamber without predators during each experiment to ensure that weight changes in treated and control cubes were equivalent and minimal (< $5 \%$ change). A slight weight gain was usually observed for cubes that were not exposed to predators because the agar absorbed water. A 1-tailed t-test for paired comparisons was used to analyze the results (Sokal \& Rohlf 1981).

Field experiments were conducted by 2 methods: (1) treating pieces of squid fillets with the extracts and isolated metabolites; and (2) incorporating the extracts and metabolites into an artificial diet consisting of carrageenan and ground squid. These 2 diets were eaten by different types of predatory fishes. Only wrasses, emperors, and triggerfishes could consume the relatively tough squid fillets. Other generalists such as 
sergeant majors and small wrasses primarily consumed the artificial diet.

Feeding deterrence against generalist predators was tested using squid fillets at 2 sites: Fingers Reef, inside Apra Harbor; and Haps Reef, facing the open ocean (Fig. 1). To prepare a field assay, sets of 4 pieces of thin squid fillets (dried with paper towels), ca $1.5 \mathrm{~cm}^{2}$, were individually attached by paper clips to polypropylene ropes $0.5 \mathrm{~m}$ in length. Extracts or isolated metabolites were diluted in a volatile solvent, diethyl ether, acetone, or 1:1 acetone:methanol, and injected and coated on the squid pieces. Control ropes were made by injecting and coating 4 squid pieces with solvent only.

Field assays were also conducted with the artificial diet at Fingers Reef. Similar methods have been used in the Caribbean to test extracts and isolated metabolites of gorgonians (Harvell et al. 1988). The artificial diet consisted of carrageenan $(2.5 \mathrm{~g})$, wax $(4.0 \mathrm{~g})$, and ground squid $(2.0 \mathrm{~g})$ which was heated to dissolve the carrageenan and melt the wax. Extracts and isolated metabolites were dissolved in diethyl ether and mixed into the squid diet when it was warm. A similar amount of ether was added to the control diet. The mixture was poured into a mold to form $1.5 \mathrm{~cm}^{3}$ cubes. Small rubber O-rings were set into the mold before the mixture gelled. The O-rings were used to attach the food mixture to safety pins on polypropylene lines. Four pieces of treated diet were attached to one line, and 4 pieces of control diet were attached to another line to form pairs of lines that were then placed on the reef.

Scuba was used to conduct both types of field assays. Matched pairs of ropes, consisting of one treated rope and one control rope, were attached to the reef at 3 to $6 \mathrm{~m}$ depth. In each assay, 12 to 20 pairs were used with each pair placed several meters apart. When at least 4 pieces of squid or artificial diet were consumed from a pair, the numbers of control and treated pieces eaten from that pair were recorded. Data were analyzed with the Wilcoxon Signed-Ranks test for paired comparisons (1-tailed) (Sokal \& Rohlf 1981). Assays lasted ca 15 to $20 \mathrm{~min}$, and compounds remained on the squid throughout the assays as confirmed by TLC after the assays were completed.

\section{RESULTS}

\section{Nudibranch field studies}

Over the 10 mo period there was a gradual increase in the number of Glossodoris pallida per Hyrtios erectaA, ranging from 1.0 on December 12,1987 to 3.4 on July 13, 1988 (Table 1 ). Some of the tagged $H$. erecta-A died, and this may have caused the higher numbers of
Table 1. Number of Glossodoris pallida on Hyrtios erecta-A. $\mathrm{N}$ : number of sponges examined. $\mathrm{CD}=\mathrm{s}^{2} / \bar{Y}=$ coefficient of dispersion. We test the hypothesis that nudibranchs are randomly distributed by assessing $\mathrm{H}_{0}: \sigma^{2}=\mu$ with a Chi-square test

\begin{tabular}{|llllll|}
\hline $\begin{array}{l}\text { Date } \\
(1987-88)\end{array}$ & $N$ & $\bar{Y}$ & SD & CD & Significance \\
\hline Oct 27 & 35 & 1.97 & 1.54 & 1.21 & $\mathrm{~ns}$ \\
Nov 10 & 42 & 1.24 & 1.46 & 1.73 & $\mathrm{p}<0.005$ \\
Nov 18 & 35 & 1.51 & 1.63 & 1.77 & $\mathrm{p}<0.005$ \\
Dec 2 & 44 & 1.27 & 1.39 & 1.51 & $\mathrm{p}<0.025$ \\
Dec 21 & 41 & 1.05 & 1.28 & 1.57 & $\mathrm{p}<0.025$ \\
Jan 7 & 34 & 1.26 & 1.42 & 1.60 & $\mathrm{p}<0.025$ \\
Feb 11 & 32 & 1.19 & 1.42 & 1.71 & $\mathrm{p}<0.01$ \\
Mar 3 & 29 & 1.03 & 1.15 & 1.28 & $\mathrm{~ns}$ \\
Mar 18 & 22 & 1.41 & 1.74 & 2.14 & $\mathrm{p}<0.005$ \\
Mar 30 & 27 & 1.59 & 1.53 & 1.46 & $\mathrm{~ns}$ \\
Apr 7 & 24 & 1.92 & 1.79 & 1.67 & $\mathrm{p}<0.025$ \\
Apr 13 & 21 & 1.95 & 1.72 & 1.51 & $\mathrm{~ns}$ \\
Apr 27 & 24 & 2.33 & 1.52 & 1.0 & $\mathrm{~ns}$ \\
May 11 & 20 & 2.25 & 1.86 & 1.54 & $\mathrm{~ns}$ \\
May 26 & 17 & 2.00 & 1.54 & 1.19 & $\mathrm{~ns}$ \\
Jun 2 & 22 & 1.68 & 1.58 & 1.49 & $\mathrm{~ns}$ \\
Jun 14 & 15 & 1.93 & 1.83 & 1.73 & $\mathrm{p}<0.05$ \\
Jul 13 & 16 & 2.69 & 2.12 & 1.67 & $\mathrm{p}<0.05$ \\
Aug 29 & 23 & 2.44 & 1.73 & 1.23 & $\mathrm{~ns}$ \\
\hline
\end{tabular}

nudibranchs on the remaining sponges in the latter part of the study, as there were fewer sponges available for nudibranchs to graze. The number of nudibranchs on any particular sponge varied occasionally between samples by one individual, suggesting that nudibranchs occasionally moved from one sponge to another, but generally stayed on the same sponge. From October 1987 to March 1988 G. pallida showed a clumped distribution on the sponges. From April to June 1988 the nudibranchs were approximately randomly distributed (Table 1). We observed many small nudibranchs $(<5 \mathrm{~mm}$ ) and eggs on the sponges during the April and May counts. This may indicate that nudibranchs are recruiting essentially at random to individual sponges. During the periodic dives, G. pallida was never sighted on $H$. altum, a closely related sponge, or any other sponges found in the area.

Glossodoris hikeurensis was frequently found on Hyrtios erecta-C in the southern part of Guam, in or near Cocos Lagoon. G. cincta was discovered feeding naturally on 2 different sponges, $H$. erecta-C in Cocos Lagoon and $H$. altum at Sponge Mound.

\section{Laboratory preference studies}

In laboratory experiments, Glossodoris pallida significantly preferred Hyrtios erecta-A over rubble, but showed no preference between rubble and either 
Table 2. Glossodoris pallida preference tests. Individual G. pallida were offered choices between 2 objects in a tank. A 2-tailed binomial test was used to assess preference between the choices. H.e.-A $=$ Hyrtios erecta-A; H.e.-C $=$ Hyrtios erecta-C

\begin{tabular}{|c|c|c|c|c|c|}
\hline Choice-1 & No. on Choice-1 & Choice-2 & No. on Choice-2 & No. with no choice & Significance \\
\hline H.e.-A & 15 & Rock & 0 & 3 & $p<0.001$ \\
\hline H.e. $-\mathrm{C}$ & 4 & Rock & 6 & 7 & $\mathrm{p}=0.75$ \\
\hline H. altum & 7 & Rock & 1 & 5 & $\mathrm{p}=0.07$ \\
\hline H.e.-A & 9 & H.e.-C & 1 & 6 & $\mathrm{p}=0.022$ \\
\hline H.e.-A & 14 & H. altum & 1 & 2 & $\mathrm{p}=0.001$ \\
\hline H.e.-C & 3 & H. altum & 5 & 1 & $\mathrm{p}=0.73$ \\
\hline H.e.-A surface & 6 & H.e.-A matrix & 0 & 1 & $p=0.03$ \\
\hline H.e.-A grazed & 6 & H.e.-A ungrazed & 2 & 7 & $p=0.29$ \\
\hline
\end{tabular}

$H$. erecta-C or $H$. altum (Table 2). G. pallida strongly preferred $H$. erecta-A over $H$. erecta-C and $H$. altum, but displayed no preference between $H$. erecta-C and $H$. altum. G. pallida showed no preference between grazed and ungrazed pieces of $H$. erecta-A, but did prefer the surface tissue of $H$. erecta-A over the matrix (Table 2).

\section{Chemical analysis}

Table 3 shows yield of organic extract as a percentage of the dry weight of the organism for Hyrtios sponges and Glossodoris nudibranchs. The yield of extract was approximately equal in $G$. pallida and its diet sponge $H$. erecta- $A$. The metabolites in the surface and the inner matrix of the sponge appeared to be qualitatively identical by TLC analysis. However, the concentration of the crude extract of the surface layer was significantly higher, roughly double that of the matrix $(\mathrm{N}=9, t=6.8, \mathrm{p}=0.0001$, paired $t$-test $)$ (Table 3). Extracts from the surface layer were also much darker due to the presence of more pigments. No

Table 3. Mean percent yield of crude extracts by dry weight of organism. N: number of separate collections made; SD: standard deviation of the \% yield

\begin{tabular}{|lrrr|}
\hline Species & \% Yield & SD & N \\
\hline Glossodoris pallida & 14.8 & 7.8 & 19 \\
G. pallida eggs & 4.0 & 0.9 & 4 \\
G. hikeurensis & 7.8 & 3.4 & 3 \\
G. hikeurensis eggs & 8.1 & 1.3 & 2 \\
G. cincta & 10.1 & & 1 \\
Hyrtios erecta-A & 14.1 & 4.6 & 20 \\
H. erecta-A surface & 8.9 & 2.6 & 9 \\
H. erecta-A matrix & 4.7 & 1.3 & 9 \\
H. erecta-A grazed & 14.4 & 4.8 & 8 \\
H. erecta-A ungrazed & 14.0 & 5.0 & 12 \\
H. erecta-C & 5.7 & 2.3 & 3 \\
H. altum & 7.0 & & 2 \\
\hline
\end{tabular}

chemical difference in types or concentrations of secondary metabolites could be detected between grazed and ungrazed pieces of $H$. erecta-A.

Table 4 lists the major metabolites of each organism and the yield of the metabolites, when known, as a percentage of the dry weight of the organism. The major metabolites of Hyrtios erecta-A, in order of increasing polarity, were one unidentified compound, scalaradial, deoxyscalarin, and scalarin (Fig. 2). Several unidentified minor metabolites were also present. Scalaradial was present in the highest concentration at ca $2.4 \%$ dry weight of the sponge. TLC analysis of 19 $H$. erecta-A individuals indicated that the relative concentrations of metabolites varied among individual sponges, but all contained the same secondary metabolites. Investigations of grazed and ungrazed pieces of sponge indicated that these chemical variations were not related to nudibranch grazing patterns.

Table 4. Major metabolites of study organisms; - indicates values not determined

\begin{tabular}{|c|c|c|}
\hline Species & Major metabolites & $\%$ Yield \\
\hline Glossodoris pallida & $\begin{array}{l}\text { Scalaradial } \\
\text { Deoxyscalarin }\end{array}$ & $\begin{array}{l}2.5 \\
2.5\end{array}$ \\
\hline G. pallida eggs & Deoxyscalarin & 1.0 \\
\hline G. cincta & $\begin{array}{l}\text { Heteronemin } \\
\text { Episcalaradial } \\
\text { Scalaradiala }\end{array}$ & $\begin{array}{l}1.5 \\
1.0 \\
1.0\end{array}$ \\
\hline $\begin{array}{l}\text { G. hikeurensis and } \\
\text { G. cincta eggs }\end{array}$ & $\begin{array}{l}\text { Heteronemin } \\
\text { Episcalaradial }\end{array}$ & $\begin{array}{l}1.0 \\
1.0\end{array}$ \\
\hline$H$ erecta-C & $\begin{array}{l}\text { Unknown } \\
\text { Scalaradial } \\
\text { Deoxyscalarin } \\
\text { Scalarin } \\
\text { Heteronemin }\end{array}$ & $\begin{array}{c}- \\
2.4 \\
- \\
2.0 \\
1.0\end{array}$ \\
\hline $\begin{array}{l}\text { H. altum } \\
\text { This metabolite wa } \\
\text { sodoris cincta }\end{array}$ & $\begin{array}{l}\text { Heteronemin } \\
\text { und in only one coll }\end{array}$ & $\begin{array}{l}1.8 \\
\text { ion of Glos }\end{array}$ \\
\hline
\end{tabular}


The organic extract of Glossodoris pallida was similar to that of Hyrtios erecta-A and contained 2 major metabolites: scalaradial and deoxyscalarin (Table 4). Scalarin and the unidentified major and minor metabolites of $H$. erecta-A were not detected in $G$. pallida. Also, G. pallida contained relatively more deoxyscalarin than $H$. erecta-A. Fewer minor metabolites were present in the extract of $G$. pallida than in the sponge extract. Egg masses of G. pallida contained only deoxyscalarin as the major metabolite; only minor amounts of scalaradial were present.

Both Glossodoris hikeurensis and $G$. cincta contained heteronemin as a major secondary metabolite, as did their natural food sponges Hyrtios erecta-C and $H$. altum (Table 4). Both $G$. hikeurensis and $G$. cincta also contained episcalaradial which was not a major metabolite of the Hyrtios sponges. One collection of $G$. cincta also contained scalaradial which was not present in $H$. erecta-C. The egg masses of both $G$. hikeurensis and $G$. cincta contained heteronemin and episcalaradial in approximately equal concentrations.

Nudibranchs did not produce highly acidic secretions from their dorsal or ventral surfaces. Nudibranch secretions had a $\mathrm{pH}$ of 6 as indicated by $\mathrm{pH}$ indicator paper

\section{Predator deterrence}

All 7 hungry aquarium fish mouthed Glossodoris pallida, then rapidly spat them out. None of the 10 nudibranchs were ever swallowed. One nudibranch was mouthed and spat out by 5 different fish before it reached the bottom of the tank. The fish would rapidly swallow pieces of fish meat in between each nudibranch that was offered. In the field at Fingers Reef,

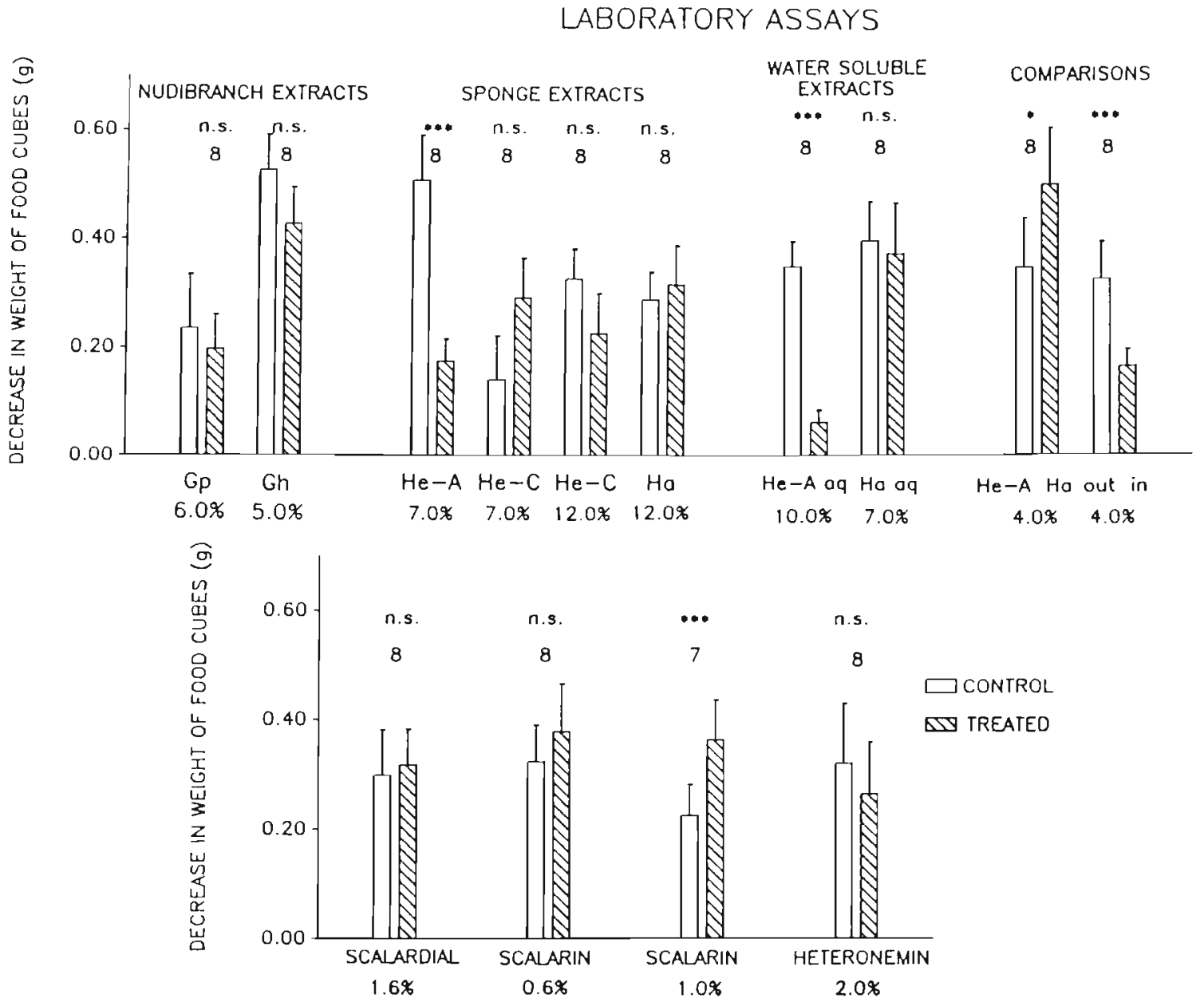

Fig. 3. Canthigaster solandri. Laboratory feeding assays. Values are reported as $\bar{Y}+1 \mathrm{SE}$. Data were analyzed by a paired $t$-test $(1$-tailed). Symbols represent: ns, not significant; $0.01<\mathrm{p}<0.05 ; \cdots \mathrm{p}<0.005$. Letters denote: Gp, Glossodoris pallida; Gh, $G$. hikeurensis; He-A, Hyrtios erecta-A; He-C, H. erecta-C; Ha, H. altum; He-A aq, water extract of H. erecta-A; Ha aq, water extract of $H$. altum; out, outer surface; in, inner matrix of $H$. erecta-A. Numbers above histograms are numbers (N) of replicate pairs used for the assay. All concentrations listed at the bottom of the histogram are in percent dry weight of food cubes 
G. pallida was rejected by sergeant majors Abudefduf spp., but nudibranchs were swallowed by several species of wrasses. Only one of 10 nudibranchs sank to the bottom without being eaten. G. pallida egg masses $(\mathrm{N}=4)$ were rapidly eaten by all fish in the field including sergeant majors and wrasses. Pieces of $\mathrm{Hyr}_{\mathrm{r}}$ tios erecta-A ( $N=5)$ were mouthed and rejected by all fish in the field, and all pieces sank to the bottom without being eaten.

Results of the feeding assays varied and depended upon which species on fish were tested. In the lab, organic extracts of Glossodoris pallida and $G$. hikeu- rensis were not deterrent toward Canthigaster solandri (Fig. 3). G. pallida was tested at $6 \%$ while G. hikeurensis was tested at $5 \%$ dry weight of the food cubes. Thus, nudibranch extracts were tested at roughly onehalf their natural concentrations. Not enough extract was available to test at a higher concentration. The $G$. hikeurensis extract tended to be avoided by some fish $(\mathrm{N}=8, \mathrm{p}=0.07$ ) so that it is possible that this extract would have been deterrent toward $C$. solandri at a higher concentration.

Both the organic and the water soluble extracts of Hyrtios erecta-A strongly deterred feeding at $7 \%$ dry

\section{FINGERS REEF}

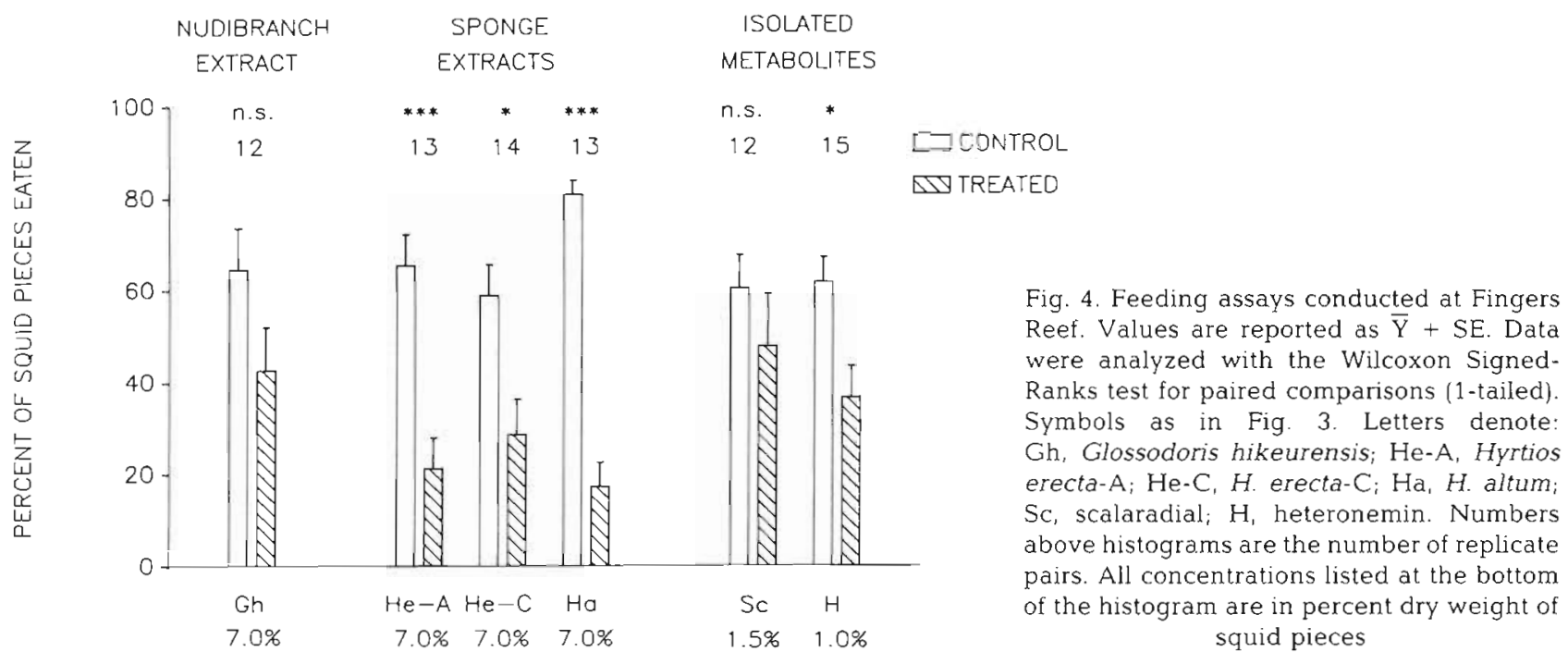

HAPS REEF

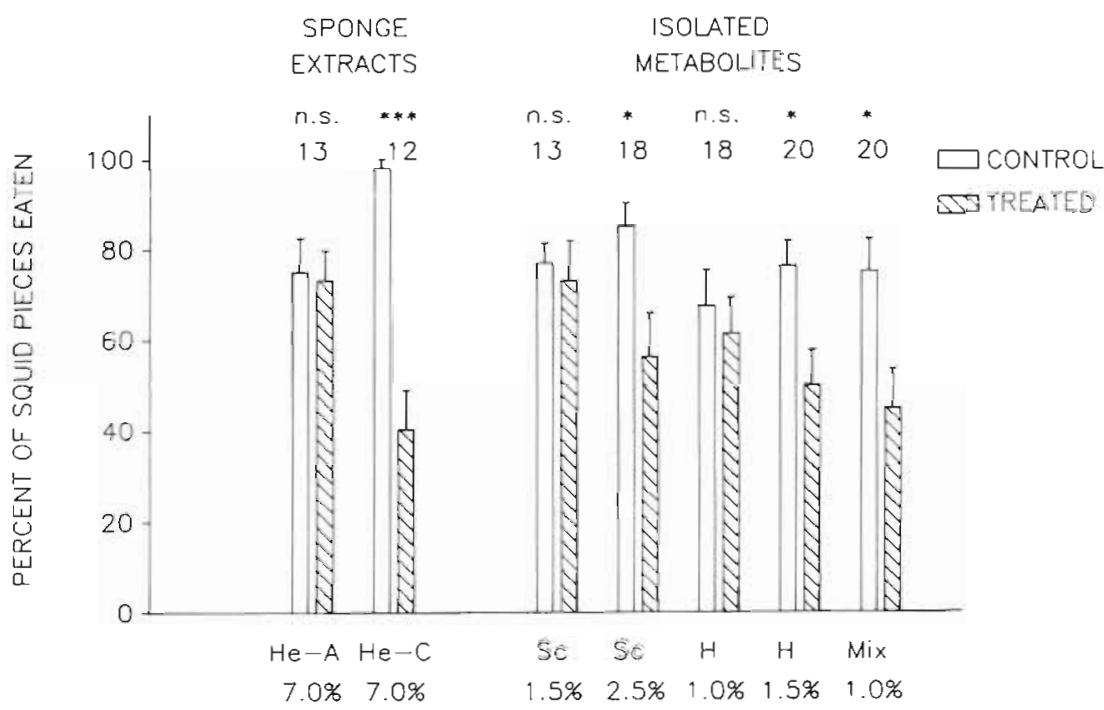

Fig. 5. Feeding assays conducted at Haps Reef. Values are reported as $\bar{Y}+S E$. Statistical tests as in Fig. 4. Symbols and letters as in Figs. $3 \& 4$. Mix $=1 \cdot 1 \mathrm{mix}$ of scalaradial: scalarin. Numbers above histograms are numbers of replicate pairs. All concentrations are in percent dry weight of squid pieces 
weight of the food tablets, slightly more than one-half of the natural concentrations in the sponge (Fig. 3). Organic extracts of $H$. erecta-C and $H$. altum did not deter feeding, even when tested at above natural concentrations. The extract from $H$. erecta-A was more deterrent than that of $H$. altum when these 2 sponges were compared; and the metabolites in the inner matrix layer of $H$. erecta-A appeared to be more deterrent than those in the surface when compared at the same concentrations.

Scalaradial, heteronemin, and scalarin were the only metabolites available in enough quantities to test for feeding deterrence against Canthigaster solandri. They were tested at $1.6 \%, 2.0 \%$ and $1.0 \%$ dry weight of the food tablet, respectively. Neither scalaradial nor heteronemin were deterrent. Scalarin significantly stimulated feeding by $C$. solandri (Fig. 3).

Feeding experiments at Fingers Reef with whole pieces of squid attracted a wide variety of fishes including several members from the families Labridae (wrasses) and Balistidae (triggerfish). Not enough extract from Glossodoris pallida was available to be tested. The extract of $G$. hikeurensis did not significantly deter feeding at $7 \%$ of squid dry weight (Fig. 4). All 3 sponges at $7 \%$, and heteronemin at $1 \%$ of squid dry weight were deterrent toward generalist predators at Fingers Reef (Fig. 4). These extracts were tested at natural concentrations or below (Table 4). Scalaradial did not deter feeding at $1.5 \%$ of squid dry weight.

At Haps Reef, one species of trigger fish, Melichthys vidua, was responsible for most of the feeding during the assays. Results of the Haps Reef assays are shown in Fig. 5. Surprisingly, the extract of Hyrtios erecta-A did not deter feeding at $7 \%$ of squid dry weight, although it was significantly deterrent at Fingers Reef and in laboratory tests. $H$. erecta-C was strongly deter-

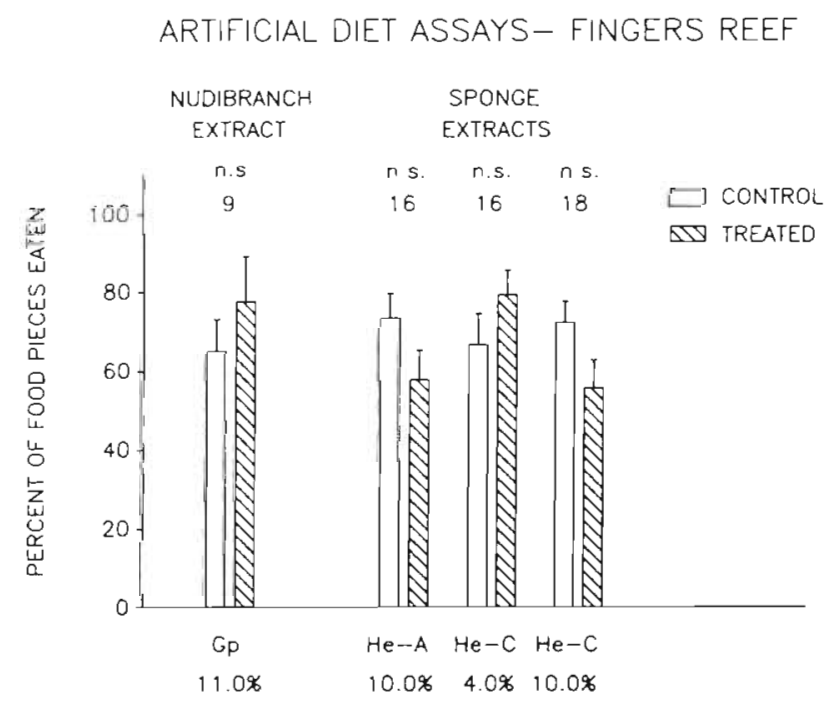

Fig. 6. Feeding assays conducted with extracts incorporated into artificial diet at Fingers Reef. Values are reported as \% of diet pieces completely eaten $(\bar{Y}+\mathrm{SE})$. Statistical tests as in Fig. 4. Symbols represent: ns, not significant; numbers below symbols indicate numbers $(\mathrm{N})$ of replicate pairs used for assays. Letters as in Figs. $3 \& 4$. Concentrations are in percent dry weight of artificial diet cubes

rent at $7 \%$. Scalaradial was not deterrent at $1.5 \%$ but was deterrent at the relatively high concentration of $2.5 \%$ of squid dry weight only at Haps Reef. Heteronemin was deterrent at $1.5 \%$ dry weight but not at $1.0 \%$. A 1:1 mixture of scalaradial and scalarin was also deterrent at the combined concentration of $1.0 \%$ dry weight.

None of the extracts or isolated metabolites were deterrent when tested in the artificial diet at Fingers Reef even though they were tested at relatively high concentrations (Figs. 6 \& 7). Neither Hyrtios erecta-A or
Fig. 7. Feeding assays conducted with isolated metabolites incorporated into artificial diet at Fingers Reef. Values are reported as \% of diet pieces completely eaten $(\bar{Y}+\mathrm{SE})$. Statistical tests are the same as in Fig. 4. Numbers below symbols indicate numbers $(N)$ of replicate pairs used for assays Letters denote: $H$, heteronemin; Sc, scalaradial; Sn, scalarin; mix scalaradial: scalarin (1 1). All concentrations are in percent dry weight of artificial diet
ARTIFICIAL DIET ASSAYS - FINGERS REEF

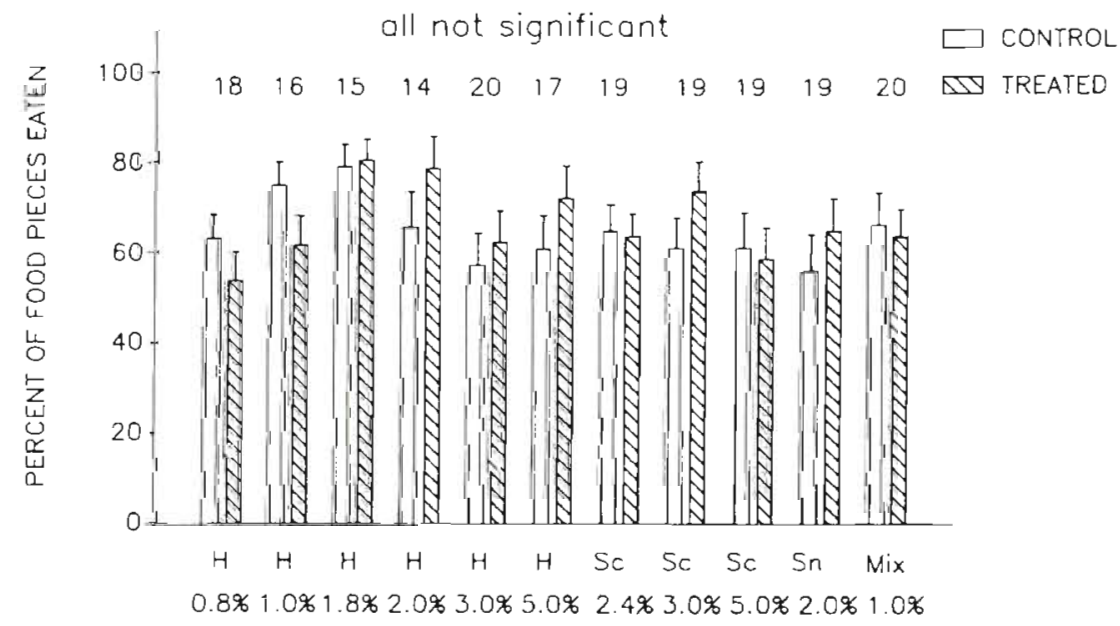


$H$. erecta-C were deterrent when tested at $10 \%$ of the dry weight of the artificial diet, although both were deterrent when tested on pieces of squid (Fig. 4). Heteronemin also was not deterrent in the artificial diet at $5 \%$ dry weight (Fig. 7), although it was deterrent on squid pieces at both Fingers Reef and Haps Reef.

\section{DISCUSSION}

On Guam, Glossodoris pallida is always found in close association with Hyrtios erecta-A while $G$. hikeurensis and $G$. cincta are most frequently found on $H$. erecta-C. In the laboratory preference tests $G$. pallida was attracted to, and strongly preferred, $H$. erectaA over $H$. erecta-C or $H$. altum. The reason for the preference of $G$. pallida is still unknown. The texture of all 3 sponges varied slightly, but probably not enough to be a major factor in the nudibranch's selection. It is possible that primary or secondary metabolites of the sponges are responsible for these preferences. Other examples of the chemical attraction of nudibranchs to their prey are known, but specific compounds involved in the chemoreception have rarely been identified (reviewed by Karuso 1987). Carté \& Faulkner (1986) showed that the nudibranch Tambje eliora is chemically attracted to its bryozoan food Sessibugula translucens and to the tambjamines, which are secondary metabolites of $S$. translucens, at low concentrations of $10^{-10} \mathrm{M}$. At higher concentrations above $10^{-8} \mathrm{M}$ the tambjamines caused avoidance by $T$. eliora.

The nudibranchs did appear to sequester some of the secondary metabolites produced by their diet sponges. The organic extract of Glossodoris pallida was very similar to that of its diet sponge Hyrtios erecta-A, indicating that G. pallida probably derives its major secondary metabolites from its food. However, some differences existed between nudibranch and sponge chemistry. G. pallida contained relatively more deoxyscalarin and did not contain any scalarin, a major metabolite of H. erecta-A. G. pallida may selectively accumulate deoxyscalarin from the sponge, or scalaradial may be converted into deoxyscalarin in the digestive gland of the nudibranch. A similar relationship has been previously described for $G$. tricolor in the Mediterranean This nudibranch feeds on the sponge Cacospongia mollior that contains scalaradial, furoscalarol, and deoxyscalarin as major metabolites. Extracts of the nudibranch contain only furoscalarol and deoxyscalarin (Cimino et al. 1982). Cimino et al. (1982) suggest that the nudibranch is able to actively convert scalaradial into deoxyscalarin.

Hungry aquarium fish and some fish in the field refused to accept healthy Glossodoris pallida as food. suggesting that the nudibranch contains feeding deter- rents. Nevertheless, some wrasses did consume nudibranchs, and nudibranch eggs were rapidly eaten by a variety of fishes in the field. Thus, it is not clear how effectively the sequestered compounds deter potential predators. It is possible that some predators are deterred by $G$. pallida metabolites such as scalaradial at high concentrations, but that many other fishes are not affected.

This hypothesis is supported by the results of the feeding assays with extracts and isolated metabolites, which were quite variable, depending largely upon which fish species were tested. The crude extract of Hyrtios erecta-A was strongly deterrent at half of its natural concentration against Canthigaster solandri in the laboratory and against general predators at Fingers Reef. Glossodoris pallida, the sponge's predator, contains many of the same major metabolites as the sponge, but did not deter $C$. solandri when tested under identical conditions. It is possible that the nudibranch extract would have been deterrent at higher concentrations or against other potential predators. The reason why the sponge extract was deterrent and the nudibranch extract was not is still unknown. We hypothesized that scalarin, a major metabolite in the sponge which was not found in the nudibranch, was responsible for the deterrence in the sponge extract. However, scalarin was shown to be a feeding attractant toward $C$. solandri. In contrast, a $1: 1$ mixture of scalarin and scalaradial was deterrent at Haps Reef at a relatively low concentration suggesting that there may be some synergistic effect of the mixture. Scalaradial, a major metabolite of both sponge and nudibranch, did not deter predators except at high concentrations at Haps Reef. Salaradial and scalarin were the only metabolites from $H$. erecta-A available for testing. It is possible that minor secondary metabolites found in the sponge extract and not in the nudibranch extract play a key role in the feeding deterrence. Several minor metabolites were noted in the sponge extract that were not present in the nudibranch extract.

Other studies of diet-derived defenses in nudibranchs suggest that the nudibranchs concentrate or enhance the secondary metabolites found in their diets (Pawlik et al. 1988, Paul et al. 1990), and that they allocate the secondary metabolites to egg masses and vulnerable body parts (Pawlik et al. 1988). This does not appear to be the case for Glossodoris pallida. Total secondary metabolite concentrations were approximately the same in Hyrtios erecta-A and in G. pallida, and egg masses contained relatively low concentrations of secondary metabolites (Table 4).

Glossodoris hikeurensis and $C$. cincta can be found on both Hyrtios erecta-C and $H$. altum in the field. Both of these sponges contain heteronemin as the major metabolite. Heteronemin was a major metabolite in 
these 2 nudibranch species; however, episcalaradial was also a major secondary metabolite in the nudibranchs and their egg masses although this was only a minor metabolite in $H$. erecta-C.

The chemistry of Hyrtios erecta- $\mathrm{C}$ and $\mathrm{H}$. altum were similar, and the results of the feeding assays of these 2 sponges were also similar. Neither the sponge extracts nor their major metabolite, heteronemin, were deterrent when tested against Canthigaster solandri in the laboratory. However, extracts of both sponges and their major metabolite were significantly deterrent when tested on squid fillets against generalist predators at Fingers Reef and Haps Reef. Heteronemin may be essential to the sponges and the nudibranchs in deterring many potential predators. Surprisingly, none of the extracts or isolated metabolites deterred fishes that consumed the artificial carrageenan diet at Fingers Reef. The different results for the squid and artificial diet assays at Fingers Reef could occur because of the different predators that consumed these 2 diets, or because of a difference in the attractiveness of the 2 diets to predators making it easier to deter fishes feeding on the squid fillets.

Glossodoris pallida is a white nudibranch that feeds on a black sponge. However, Glossodoris nudibranchs are found attached underneath or in a notch of their host sponge where they are at least partially hidden from predators. The nudibranch color matches that of the sponge inner matrix which is exposed when the nudibranchs graze. Consequently, Glossodoris nudibranchs are potentially hidden from predators while they feed. Since the nudibranch's diet sponges probably have few predators, the nudibranchs are at little risk of being eaten by most predators. Contrary to what is typically proposed for nudibranchs, G. pallida appear to break down or excrete some of the noxious compounds consumed in their diet, rather than accumulate them for their own protection, since they are only partially chemically defended from predators. At the same time, they are partially protected from predation by hiding in a noxious sponge. Thus, while feeding on Hyrtios sponges, Glossodoris nudibranchs appear to be taking advantage of, and receiving protection from, an available food source. Similarly, many herbivores may specialize upon certain host plants to avoid predators that do not forage on those plants (Bernays \& Graham 1988, Hay \& Fenical 1988, Hay et al. 1988, 1989).

This study demonstrates that the relationships between Hyrtios sponges, the Glossodoris nudibranchs, and higher order predators are complex. The 3 Glossodoris species we examined do not passively sequester compounds from their diet sponges. Some compounds such as scalarin are not sequestered, some are changed, and others such as deoxyscalarin and episcalaradial are enhanced in concentration. These changes in the sequestered sponge metabolites did not appear to enhance the chemical defenses of the Glossodoris nudibranchs, since extracts from the nudibranchs did not deter potential predators at the same concentrations that sponge extracts did (half of natural concentrations). It is possible that nudibranch extracts would have been deterrent at higher concentrations, since the major secondary metabolites scalaradial and heteronemin sometimes deterred fishes at high concentrations. It is clear that the nudibranch chemical defenses vary in effectiveness depending on the predator. In addition, simply living on a noxious sponge may be an important defense for the Glossodoris nudibranchs.

Acknowledgements. We are indebted to Dr Pat Bergquist for identifying the sponges used in this study and to Clay Carlson for identifying the nudibranchs. We thank $C$. Birkeland, $J$. Faulkner, C. D. Harvell, J. Marsh, J. Pawlik, S. Pennings, M. Rogers, and R. Richmond for their comments on drafts of this manuscript. C. Birkeland, B. Smith, S. Wilkins, K. Kuetzing and $B$. Irish assisted with statistical analyses, computer programs, and field and laboratory experiments. D. Norris helped with preparation of the figures. This work was supported by a grant from the National Institutes of Health \#GM38624 to V.J.P. and is contribution \#308 of the University of Guam Marine Laboratory

\section{LITERATURE CITED}

Amesbury, S. S., Myers, R. F. (1982). Guide to the coastal resources of Guam, Vol. 1. The fishes. Univ. of Guam Mar Lab. Contr No. 173. Mangilao, Guam, p. 1-141

Bakus, G. J. (1981). Chomical defense mechanisms on the Great Barrier Reef, Australia. Science 211. 497-499

Bakus, G. J., Targett, N. M. Schulte, B. (1986). Chemical ecology of marine organisms: an overview. J. chem. Ecol 12: 951-987

Bergquist, P. R. (1980). A revision of the supraspecific classification of the orders Dictyoceratida, Dendroceratida, and Verongrda (class Desmospongiae). N.Z. Jl Zool. 7 . 443-503

Bergquist, P. R., Wells, R. J. (1983). Chemotaxonomy of the Porifera: the development and current status of the field. In: Scheuer, P. J. (ed.) Marine natural products, Vol. 5. Academic Press, New York, p. 1-50

Bernays, E., Graham, M. (1988). On the evolution of host specificity in phytophagous arthropods. Ecology 69 : 886-892

Carté, B., Falkner, D. J. (1986). Role of secondary metabolites in feeding associations between a predatory nudibranch, two grazing nudibranchs, and a bryozoan. J. chem. Ecol. 12: 795-804

Cimino, G., De Rosa, S., De Stefano, S., Morrone, R., Sodano, G. (1985). The chemical defense of nudibranch molluscs. Structure, biosynthetic origin and defensive properties of terpenoids from the dorid nudibranch Dendrodoris grandiflora. Tetrahedron 41: 1093-1100

Cimino, G., De Rosa, S., De Stefano, S., Sodano, G. (1982). The chemical defense of four Mediterranean nudibranchs Comp. Biochem. Physiol. 73B: 471-474

Cimino, G., De Stefano, S., Minale, L. (1974). Scalaradial, a 
third sesterterpene with the tetracarbocyclic skeleton of scalarin, from the sponge Cacospongia mollior. Experientia 30: 846-847

Crews, P., Bescansa, P. (1986). Sesterterpenes from a common marine sponge Hyrtios erecta. J. nat. Products 49: $1041-1052$

Crews, P., Bescansa, P., Bakus, G. J. (1985). A non-peroxide norsesterterpene from a marine sponge Hyrtios erecta. Experientia 41: 690-691

Crossland, C. (1911). Warning coloration in a nudibranch mollusc and in a chameleon. Proc. zool. Soc. Lond. 79: 1062.

Edmunds, M. (1968). Acid secretion in some species of Doridacea (Mollusca, Nudibranchia). Proc. malac. Soc. Lond. 38: 121-132

Faulkner, D. J. (1984). Marine natural products: metabolites of marine invertebrates. Nat. Product Rep. (Lond.) 1 551-598

Faulkner, D. J. (1988). Feeding deterrents in molluscs. In: Fautin, D. G. (ed.) Biomedical importance of marine organisms. Mem. Calif. Acad. Sci. 13: 29-36

Faulkner, D. J. (in press). Chemical defenses in marine molluscs. In: Paul, V J. (ed.) Ecological roles of marine secondary metabolites. Cornell Univ. Press, Ithaca

Faulkner, D. J., Ghiselin, M. T. (1983). Chemical defense and evolutionary ecology of dorid nudibranchs and some other opisthobranch gastropods. Mar. Ecol. Prog. Ser. 13: 295-301

Faulkner, D. J., Molinski, T. F., Anderson, R. J., Dumdei, E. J., de Silva, E. D. (1990). Geographical variation in defensive chemicals from Pacific coast dorid nudibranchs and some related marine molluscs. Comp. Biochem. Physiol. 97C: $233-240$

Gunthrope, L., Cameron, A. M. (1987). Bioactive properties of extracts from Australian dorid nudibranchs. Mar. Biol. 94: $34-39$

Gustafson, K., Anderson, R. J., Chen, M. H. M., Clardy, J., Hochlowski, J. E. (1984). Terpenoic acid glycerides from the dorid nudibranch Archidoris montereyensis. Tetrahedron Lett. 25: 11-14

Harvell, C. D.,Fenical, W., Greene, C. H. (1988). Chemical and structural defenses of Caribbean gorgonians (Pseudopterogorgia spp.). I. Development of and in situ feeding assay. Mar. Ecol. Prog. Ser. 49: 287-294

Hay, M. E., Fenical, W (1988). Marine plant-herbivore interactions: the ecology of chemical defense. A. Rev. Ecol. Syst. 19: 111-145

Hay, M. E., Pawlik, J. R., Duffy, J. E. (1989). Seaweed-herbi-

This article was presented by C. Birkeland, Mangilao, Guam vore-predator interactions: host plant specialization reduces predation on small herbivores. Oecologia 81 : 418-427

Hay, M. E., Renaud, P. E., Fenical, W. (1988). Large mobile versus small sedentary herbivores and their resistance to seaweed chemical defenses. Oecologia $75: 246-252$

Herdman, W. A., Clubb, J. A. (1892). Third report on the nudibranchiata of the L.M.B.C. district. Proc. Lpool biol. Soc. 4: $131-169$

Karuso, P. (1987). Chemical ecology of the nudibranchs. In: Scheuer, P. J. (ed.) Bioorganic marine chemistry. SpringerVerlag, New York, p. 31-60

Kazlauskas, R., Murphy, P. T., Quinn, R. J., Wells, R. J. (1976). Heteronemin, a new scalarin type sesterterpene from the sponge Heteronema erecta. Tetrahedron Lett. 1976: 2631-2634

Minale, L. (1978). Terpenoids from marine sponges. In Scheuer, P. J. (ed.) Marine natural products: chemical and biological perspectives, Vol. I. Academic Press, New York, p. $175-240$

Okuda, R. K., Scheuer, P. J. (1985). Latrunculin-A, ichthyotoxic constituent of the nudibranch Chromodoris elisabethina. Experientia 41 1355-1356

Paul, V. J., Lindquist, N., Fenical, W. (1990). Chemical defenses of the tropical ascidian A tapozoa sp. and its nudibranch predators Nembrotha spp. Mar Ecol. Prog. Ser. 59: $109-118$

Pawlik, J. R., Kernan, M. R., Molinski, T F., Harper, M. K., Faulkner, D. J. (1988). Defensive chemicals of the Spanish dancer nudibranch Hexabranchus sanguineus and its egg ribbons: macrolides from a sponge diet. J. exp. mar. Biol. Ecol. 119: 99-109

Rogers, S. D. (1989). Feeding preferences and chemical defenses of three Glossodoris nudibranchs and their diet sponges. M.Sc. thesis, Univ. of Guam

Schulte, G., Scheuer, P. J., McConnell, O. J. (1980). Two furanosesquiterpene marine metabolites with antifeedent properties. Helv. chim. Acta 63: 2159-2167

Sokal, R. R., Rohlf, F. J. (1981). Biometry, 2nd edn. W H Freeman and Co, New York

Thompson, J. E., Walker, R. P., Wratten, S. J., Faulkner, D. J (1982). A chemical defense mechanism for the nudibranch Cadlina luteomarginata. Tetrahedron 38: 1865-1873

Thompson, I E. (1960). Defensive adaptation in opisthobranchs. J. mar biol. Ass. U.K. 39: 123-134

Thompson, T. E. (1976). Biology of the opisthobranchs, Vol. I. Ray Society, London

Manuscript first received: April 23, 1991

Revised version accepted: September 3,1991 